\title{
Avaliação da corrosão sob tensão em aço inoxidável AISI 321 em ambiente de reator nuclear
}

\author{
SCHVARTZMAN ${ }^{\mathrm{I}}$, M.M.A.M.; MATIAS ${ }^{\mathrm{II}}$, ADALBERTO; CRUZ ${ }^{\mathrm{III}}$, J.R.B.

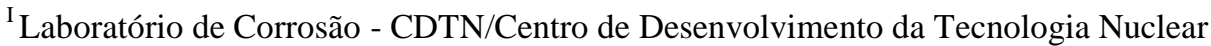 \\ Av. Antônio Carlos 6627, Pampulha, CEP: 30.161-970, Belo Horizonte, MG. \\ e-mail: monicas@cdtn.br \\ ${ }^{\text {II }}$ Petrobrás, Av. República do Chile, 65, Centro, CEP: 20031-170, Rio de Janeiro - RJ. \\ email: amatias@petrobras.com.br

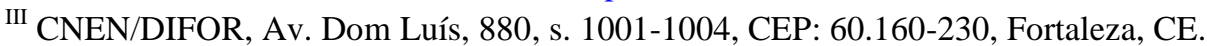 \\ e-mail: jrcruz@cnen.gov.br
}

\section{RESUMO}

Este trabalho tem como objetivo avaliar a suscetibilidade à corrosão sob tensão do aço inoxidável austenítico AISI $321 \mathrm{em}$ ambiente similar ao de um reator nuclear. Utilizou-se o ensaio de taxa de deformação lenta - SSRT (Slow Strain Rate Test), que é um dos métodos mais recentes desenvolvidos para avaliar o processo de CST (Corrosão Sob Tensão) em laboratório. Os ensaios foram realizados à temperatura de $288^{\circ} \mathrm{C}$ e pressão de $8 \mathrm{MPa}$, em meio aquoso, contendo $1000 \mathrm{ppm}$ de B e 2,2 ppm de Li, e em atmosfera inerte $\left(\mathrm{N}_{2}\right)$. Os resultados indicaram que a taxa de deformação de $3 \times 10^{-7} \mathrm{~s}^{-1}$ é adequada para realizar avaliações comparativas do processo de CST utilizando o ensaio de SSRT e que o aço AISI 321 apresenta baixa suscetibilidade à CST nas condições estudadas.

Palavras-chaves: corrosão sob tensão (CST), AISI 321, ensaio de taxa de deformação lenta.

\section{Stress corrosion cracking of 321 stainless stell in nuclear reactor environment}

\section{ABSTRACT}

The aim of this work is to evaluate the stress corrosion cracking (SCC) susceptibility of AISI 321 steel under environmental conditions similar to those of a nuclear power plant. The evaluation was performed using the slow strain rate test (SSRT) method, which is one of the most recent techniques developed to evaluate the SCC process in laboratory. The tests were performed under temperature of $288{ }^{\circ} \mathrm{C}$ and pressure of $8 \mathrm{MPa}$, in water environment (containing $1000 \mathrm{ppm}$ of $\mathrm{B}$ and 2,2 ppm de Li) and in inert atmosphere $\left(\mathrm{N}_{2}\right)$. The results indicated that the strain rate of $3 \times 10^{-7} \mathrm{~s}^{-1}$ is adequate to perform comparative evaluations of the SCC process using the SSRT test. They also revealed that the AISI321 steel presents a low susceptibility to SCC for the analyzed conditions.

Keywords: stress corrosion cracking, slow strain rate test, AISI 321.

\section{INTRODUÇÃO}

A degradação de materiais estruturais é um dos principais fatores técnicos que podem limitar a eficiência das centrais nucleares modificando suas características com o tempo ou uso. Um importante mecanismo de degradação que atinge os componentes de centrais nucleares é a corrosão sob tensão (CST). Este fenômeno ocorre em materiais que apresentam boa resistência à corrosão generalizada, tais como aços inoxidáveis austeníticos, ligas de alumínio, ligas de níquel, etc., sendo geralmente associado à presença de tensões mecânicas, aplicadas ou residuais, um meio corrosivo específico e um material suscetível. As taxas de corrosão resultantes são geralmente baixas e as tensões nominais que causam CST estão freqüentemente abaixo do limite de escoamento do material. A CST se caracteriza pela formação de trincas que favorecem a 
ruptura brusca do material, sendo um dos mecanismos de degradação mais severos que influenciam no tempo de vida de componentes metálicos [1] .

A suscetibilidade de ligas metálicas à CST depende de fatores como, composição química, microestrutura, processo de fabricação e tratamento térmico sofrido pelo material. Os teores de carbono e cromo aparecem como variáveis importantes quando se avalia a composição química. O tamanho de grão e a presença e localização de inclusões e precipitados são também variáveis relevantes na avaliação da resistência de materiais a este fenômeno [2].

Duas principais fontes de tensão são capazes de promover o processo de CST, as tensões resultantes das condições de operação (pressão, temperatura e carregamento mecânico) e as tensões residuais (provenientes de soldagem, operações de conformação mecânica, tratamento mecânico superficial, transformações de fase, etc.). As tensões existentes durante a operação são consideradas nos projetos das plantas nucleares e devem obedecer a normas e códigos específicos. Entretanto, elevadas tensões residuais podem ser criadas durante os processos de fabricação e de soldagem. As tensões residuais decorrentes da soldagem podem ser maiores do que as tensões de operação e tendem a ser uma força motriz dominante para a iniciação e o crescimento de trincas por CST [3]].

O meio e a temperatura de operação também são fatores que contribuem de maneira marcante para a CST. As concentrações de oxigênio e hidrogênio, o potencial de corrosão e o pH da solução desempenham um importante papel neste processo. Locais que operam a elevadas temperaturas exibem trincas mais rapidamente do que regiões onde existam menores temperaturas. Este processo é ativado termicamente e pode ser representado pela lei de Arrhenius [ $\underline{3}-\underline{4}]$.

Trincas decorrentes deste processo corrosivo podem ser transgranulares ou intergranulares. Porém, macroscopicamente, são sempre perpendiculares ao sentido de aplicação das tensões. Fraturas transgranulares são menos comuns que as intergranulares, mas ambas podem existir em um mesmo sistema ou na mesma região falhada, dependendo das condições existentes. O comportamento da falha é característico daquele apresentado por um material frágil, embora as ligas metálicas normalmente suscetíveis

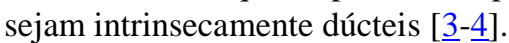

A maioria dos reatores nucleares em operação no mundo ocidental utiliza como refrigerante a água e como combustível o urânio enriquecido. Estes são chamados de reatores LWR (Light Water Reactors) e possuem componentes fabricados com materiais como aços inoxidáveis e ligas de níquel. Estes materiais são suscetíveis à CST nas condições de operação destes reatores, pois estão sujeitos a tensões de tração e a elevadas pressões e temperaturas de operação [5]. Este tipo de trincamento surge somente após muitos anos de operação, sendo que para a liga de níquel 600 a iniciação de trincas começou a ser observada nos reatores comerciais tipo LWR após cerca de 20 anos de operação [3]].

Para avaliar o tempo de vida residual de um componente danificado ou que opera em condições suscetíveis à CST, é necessário determinar os parâmetros do processo de degradação, utilizando ensaios padronizados e técnicas experimentais desenvolvidas especialmente para esse objetivo [ㅈ,]. Uma importante característica dos ensaios de CST é a de fornecer informações mais rápidas do que podem ser obtidas através de experiências em serviço. O ensaio de taxa de deformação lenta (SSRT - Slow Strain Rate Testing) constitui-se em um tipo de ensaio utilizado para verificar a suscetibilidade de um material à CST. É um dos métodos mais recentes desenvolvidos para acelerar o processo de CST em laboratório, sendo um caso particular de ensaio de tração sob taxa de deformação lenta, em que o corpo-de-prova (CP) fica exposto a condições ambientais apropriadas. Por ser um ensaio acelerado, os resultados não representam, necessariamente, as condições em serviço, mas fornecem bases para realizar avaliações comparativas de efeitos metalúrgicos e do meio no processo de trincamento por CST [7-9].

Os principais tipos de reator LWR são o PWR (Pressurized Water Reactor) e o BWR (Boiling Water Reactor). Ambos utilizam água comum como refrigerante e moderador de nêutrons. A diferença básica é que os reatores do tipo PWR utilizam um circuito de água sob alta pressão para refrigerar o núcleo do reator, de forma que nesse circuito, chamado de circuito primário, a água é mantida em estado líquido. A temperatura da água no circuito primário varia de $296^{\circ} \mathrm{C}$ a $350^{\circ} \mathrm{C}$ e a pressão de operação entre 10 e $15 \mathrm{MPa}$. Nesse tipo de reator, o vapor que alimenta as turbinas é gerado em trocadores de calor (chamados de geradores de vapor) que ficam na interface entre dois sistemas fechados: o circuito primário e o circuito secundário, sendo este último o que transporta o vapor para as turbinas. Já nos reatores tipo BWR, existe apenas um circuito onde a água se encontra a uma pressão bem inferior à de um reator PWR, ocorrendo sua ebulição no núcleo a uma temperatura em torno de $285^{\circ} \mathrm{C}$. O vapor, portanto, é gerado no núcleo e segue diretamente para as turbinas [10].

Neste artigo, determinou-se a taxa de deformação mais adequada para se estudar o processo de corrosão sob tensão do aço AISI 321 utilizando o ensaio de taxa de deformação lenta e avaliou-se, por comparação, a suscetibilidade à corrosão sob tensão deste aço, em meio aquoso similar ao de um reator nuclear PWR e em meio neutro $\left(\mathrm{N}_{2}\right)$, à temperatura de $288^{\circ} \mathrm{C}$. 


\section{MATERIAIS E MÉTODOS}

\subsection{Instalação}

A instalação de CST foi projetada e construída para operar em condições similares aos circuitos dos reatores tipo LWR. Foi desenvolvida como um sistema universal para todos os principais ensaios de corrosão sob tensão, conforme normas da ASTM, ISO e DIN. Ela é composta de uma autoclave com um sistema de tração servohidráulico, controlado por deslocamento ou carga, e de um circuito hidráulico com um sistema de circulação do meio aquoso [11]. O deslocamento é medido por meio de um sensor de posição linear (método: linear variable differential transformer - LVDT) e a carga por meio de uma célula de carga. O sistema de aquecimento da autoclave é constituído por um forno elétrico controlado continuamente por um sistema PID (Proporcional - Integral - Diferencial).

Durante a execução do experimento são realizadas medições on line de carga, deslocamento, temperatura e pressão. Um software de aplicação desenvolvido no ambiente LabVIEW ${ }^{\circledR}$ é responsável pela aquisição de dados e sua representação gráfica. A instalação permite a utilização de corpos-de-prova (CP) de tração e de tração compacto $(\mathrm{CT})$ pré-trincados por fadiga. O CP é isolado eletricamente do resto do sistema por meio de pinos anodizados. A Figura 1 mostra um diagrama esquemático da instalação de CST utilizada nos ensaios.

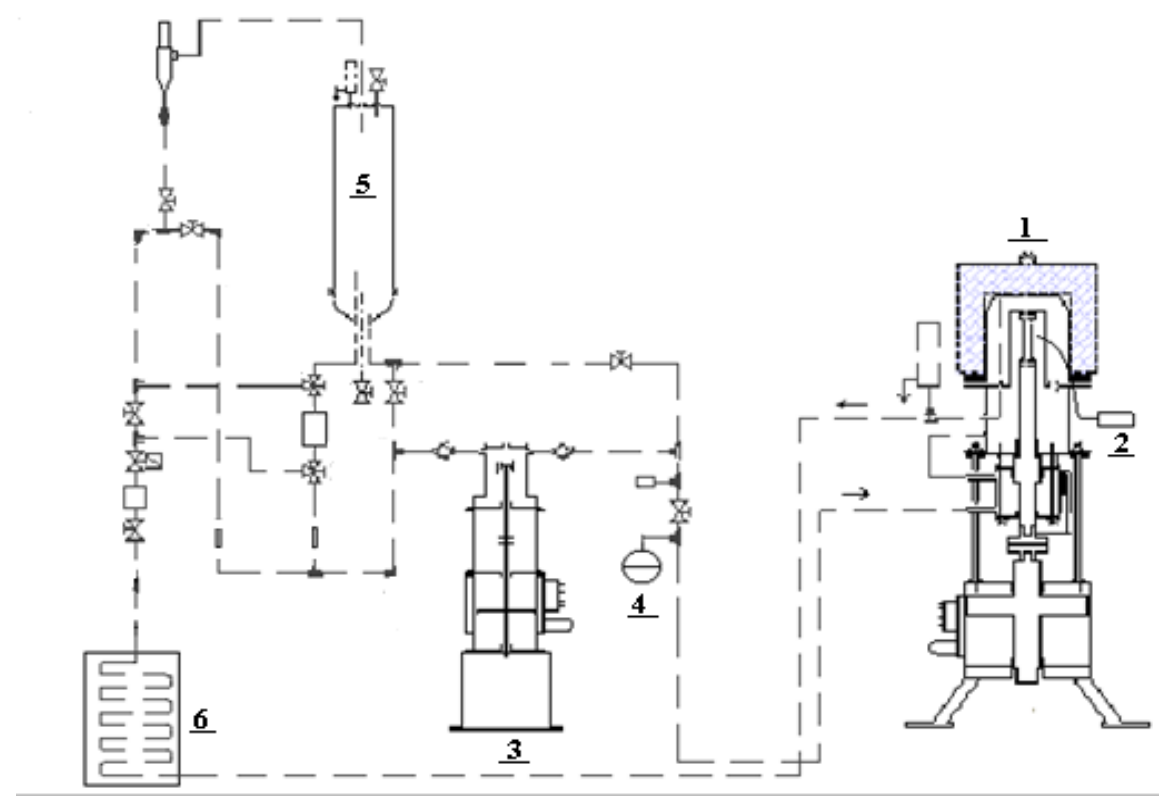

Figura 1: Diagrama esquemático da instalação de CST: 1) autoclave; 2) eletrodo de Pt; 3) bomba de circulação do meio; 4) acumulador de pressão; 5) tanque de armazenamento do meio; 6) cooler.

\subsection{Material}

Para execução dos ensaios, corpos-de-prova foram retirados de uma chapa de aço inoxidável AISI 321. A composição química e a microestrutura do material são apresentadas na Tabela 1 e na Figura 2, respectivamente. $\mathrm{O}$ ataque eletrolítico para revelação da microestrutura foi realizado com ácido oxálico $10 \%$, utilizando-se corrente de $1 \mathrm{~A}$ durante 90 segundos $\mathrm{O}$ material possui uma microestrutura austenítica de grãos equiaxiais, com alguns precipitados de carboneto e maclas. O tamanho médio de grão é de aproximadamente $10 \mu \mathrm{m}$.

Tabela 1: Composição química do aço AISI 321 (\% peso). Balanço: Fe.

\begin{tabular}{|c|c|c|c|c|c|}
\hline $\mathrm{Cu}$ & $\mathrm{Mn}$ & $\mathrm{Cr}$ & $\mathrm{Ni}$ & $\mathrm{Mo}$ & $\mathrm{Ti}$ \\
\hline 0,08 & 0,99 & 18,1 & 10,1 & 0,18 & 0,41 \\
\hline
\end{tabular}




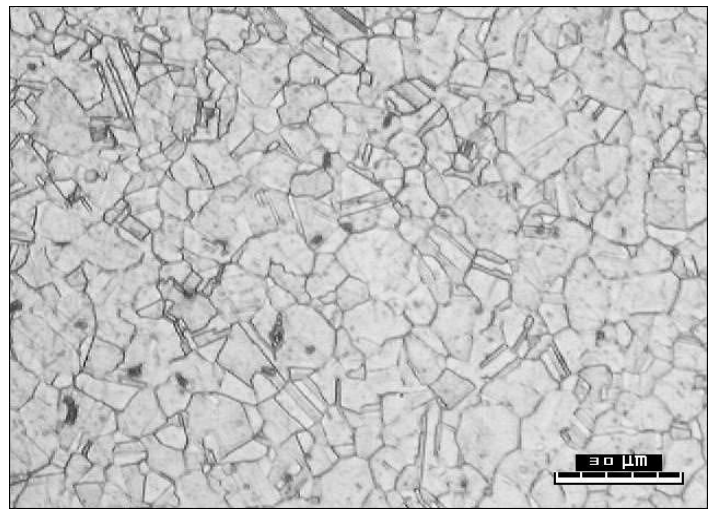

Figura 2: Microestrutura do aço AISI 321. 500X. Ataque eletrolítico: ácido oxálico 10 \%, 90 s.

A Tabela 2 apresenta as propriedades mecânicas do aço AISI 321, como recebido, obtidas à $25^{\circ} \mathrm{C}$.

Tabela 2: Propriedades mecânicas do aço inoxidável 321 à $25^{\circ} \mathrm{C}$.

\begin{tabular}{|c|c|c|c|}
\hline Temperatura $\left({ }^{\circ} \mathrm{C}\right)$ & $\sigma_{\mathrm{YS}}(\mathrm{MPa})$ & $\sigma_{\mathrm{UTS}}(\mathrm{MPa})$ & Deformação $(\%)$ \\
\hline 25 & 234 & 641 & 43,7 \\
\hline
\end{tabular}

$\sigma_{\mathrm{YS}}$ - limite de escoamento; $\sigma_{\mathrm{UTS}}$ - limite de resistência.

\section{$2.3 \quad$ Meio}

O meio utilizado nos ensaios de CST foi uma solução aquosa contendo ácido bórico e hidróxido de lítio. A Tabela 3 mostra a composição química da solução aquosa empregada nos ensaios.

Tabela 3: Composição da química da água empregada nos ensaios de CST.

\begin{tabular}{|c|c|}
\hline Parâmetro de controle & Valores \\
\hline Cloretos $(\mathrm{ppb})$ & $<50$ \\
\hline Fluoretos $(\mathrm{ppb})$ & $<50$ \\
\hline Sulfatos $(\mathrm{ppb})$ & $<50$ \\
\hline Boro $(\mathrm{ppm})$ & 1200 \\
\hline Lítio $(\mathrm{ppm})$ & 2,2 \\
\hline
\end{tabular}

\subsection{Ensaio de corrosão sob tensão}

O ensaio de taxa de deformação lenta, SSRT (Slow Strain Rate Test) é empregado para avaliar a suscetibilidade à CST de materiais metálicos em diferentes meios corrosivos. Este é um ensaio comparativo que deve ser conduzido em pelo menos dois meios: (i) em um meio neutro (meio no qual o material não é suscetível à CST); (ii) no meio de interesse, no qual a resistência à CST está sendo determinada. Alguns exemplos de meios neutros para a maioria dos materiais metálicos são: ar seco, gases inertes secos (He, Ar), óleo de silicone, vácuo ou, em alguns casos, $\mathrm{N}_{2}$ seco [12]. É um dos métodos desenvolvidos para acelerar o processo de CST em laboratório, sendo um caso particular de ensaio de tração sob taxa de deformação lenta, com o corpo-de-prova (CP) exposto a condições ambientais apropriadas.

Este ensaio consiste em submeter o $\mathrm{CP}$ a esforços de tração, com taxa de deformação constante no meio em estudo e em meio neutro. Parâmetros relacionados à variação de ductilidade do material (tempo de falha, deformação plástica ou total) e limite de resistência obtidos nas curvas tensão versus deformação, a observação visual da região fraturada e a morfologia da fratura são utilizados como indicadores da resistência do material à CST no meio estudado. Os resultados obtidos no meio estudado são comparados com os resultados de um ensaio conduzido em um ambiente em que o material não sofre corrosão sob tensão para eliminar o efeito do meio no processo de CST do material (neste caso, ocorre apenas a fratura mecânica do material). O grau de suscetibilidade à CST é, geralmente, avaliado através da observação de diferenças no comportamento do material nos dois meios. Parâmetros como tempo de falha, redução de área do CP e indicação visual do processo de CST e, às vezes, a combinação destes parâmetros é utilizada na determinação da suscetibilidade à CST [12]. 
As taxas de deformação empregadas nos ensaios variam de $10^{-4}$ a $10^{-8} \mathrm{~s}^{-1}$, devendo ser baixa $\mathrm{o}$ suficiente para permitir a ocorrência do processo de corrosão, e ao mesmo tempo elevada, para se produzir a falha do CP em um período de tempo adequado para propósitos avaliativos. Em aplicações onde existem poucos dados de CST referentes ao material/meio de interesse particular, ensaios preliminares devem ser conduzidos, em taxas de deformação variando a partir de $1 \times 10^{-6}$, para se determinar o efeito da taxa de deformação na suscetibilidade à CST. Quando taxas muito elevadas são utilizadas, ocorrerá a fratura mecânica do material antes que as reações de corrosão necessárias ao desenvolvimento do fenômeno possam ocorrer. Entretanto, para taxas de deformação muito baixas, a corrosão pode ser suprimida devido à recomposição do filme passivo $[\underline{12}, \underline{13}]$. Assim, é importante estabelecer a taxa de deformação adequada para um determinado sistema material/meio, conforme o interesse.

Neste trabalho, os ensaios de CST com taxa de deformação lenta foram executados segundo a norma ASTM G 129-95 [12] ], utilizando CPs de tração com comprimento útil de $30 \mathrm{~mm}$ e diâmetro de 6 mm (Figura 3), confeccionados de acordo com a norma ASTM G49 [14].

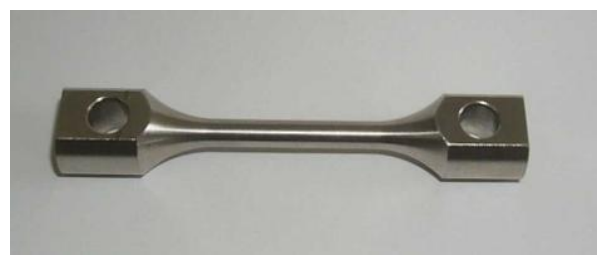

Figura 3: Corpo-de-prova utilizado nos ensaios de CST com taxa de deformação lenta.

Os ensaios de SSRT foram conduzidos à temperatura de $288^{\circ} \mathrm{C}$, pressão de $8 \mathrm{MPa}$, com circulação da solução a uma vazão de aproximadamente 0,4 1/h, com monitoramento on line de carga, deslocamento, pressão e temperatura. Primeiramente, foram realizados ensaios (ensaios 01 e 02 ) com taxas de deformação de $1 \times 10^{-6} \mathrm{~s}^{-1}$ e $3 \times 10^{-7} \mathrm{~s}^{-1}$ para verificar a mais adequada. Posteriormente, foi realizado o ensaio 03 com taxa de deformação de $3 \times 10^{-7} \mathrm{~s}^{-1}$ no meio neutro (nitrogênio), a $288^{\circ} \mathrm{C}$ e pressão de 2,0 MPa. De acordo com a norma ASTM G129 [12] o ensaio em meio neutro deve ser realizado em um ambiente controlado no qual o material não é suscetível à CST, não sendo necessário utilizar as mesmas condições de pressão do ensaio em meio aquoso. Desses ensaios foram obtidas as curvas tensão-deformação e as superfícies de fratura foram submetidas à análise por microscopia eletrônica de varredura.

\section{RESULTADOS E DISCUSSÃO}

\subsection{Avaliação da taxa de deformação}

A Figura 4 mostra as curvas tensão-deformação para o aço inoxidável AISI 321 obtidas nos ensaios de CST com taxas de $1 \times 10^{-6} \mathrm{~s}^{-1}$ e $3 \times 10^{-7} \mathrm{~s}^{-1}$ em meio aquoso, a $288^{\circ} \mathrm{C}$ e $8 \mathrm{MPa}$. As propriedades mecânicas correspondentes são apresentadas na Tabela 4. Comparando-se o comportamento em CST, observa-se que a diminuição na taxa de deformação não resultou em variação significativa nas propriedades mecânicas do material no meio estudado.

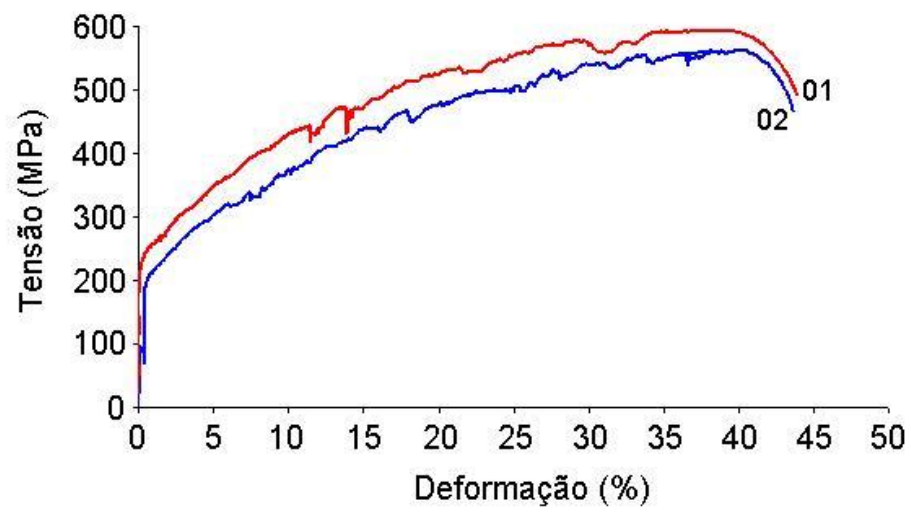

Figura 4: Curvas tensão-deformação para CPs de aço inox AISI 321. Ensaios de CST com taxa de deformação de $1 \times 10^{-6} \mathrm{~s}^{-1}$ (curva 01) e $3 \times 10^{-7} \mathrm{~s}^{-1}$ (curva 02). 
Tabela 4: Propriedades mecânicas do aço AISI 321 em meio aquoso, a $288^{\circ} \mathrm{C}$ e $8 \mathrm{MPa}$, obtidas após os ensaios de CST com diferentes taxas de deformação.

\begin{tabular}{|c|c|c|c|c|c|}
\hline Curva & $\begin{array}{c}\text { Taxa de } \\
\text { deformação }\left(\mathrm{s}^{-1}\right)\end{array}$ & $\begin{array}{c}\sigma_{\mathrm{YS}} \\
(\mathrm{MPa})\end{array}$ & $\begin{array}{c}\sigma_{\mathrm{UTS}} \\
(\mathrm{MPa})\end{array}$ & $\begin{array}{c}\text { Deformação } \\
(\%)\end{array}$ & $\begin{array}{c}\text { Tempo de } \\
\text { ruptura (h) }\end{array}$ \\
\hline 1 & $1 \times 10^{-6}$ & 225 & 590 & 43,6 & 247 \\
\hline 2 & $3 \times 10^{-7}$ & 210 & 570 & 43,7 & 413 \\
\hline
\end{tabular}

A Figura 5 mostra as superfícies de fratura e as superfícies laterais dos CPs ensaiados em meio similar ao de em reator nuclear, com taxas de deformação de $1 \times 10^{-6} \mathrm{~s}^{-1}$ e $3 \times 10^{-7} \mathrm{~s}^{-1}$. Ambas apresentaram regiões de iniciação e propagação de trincas por CST, como as indicadas pelas setas. O CP ensaiado com a taxa de deformação de $1 \times 10^{-6} \mathrm{~s}^{-1}$ apresentou regiões dispersas de iniciação de trincas que ficaram restritas à borda do material (Figura 8a), e tiveram profundidade máxima de penetração de $250 \mu \mathrm{m}$. As superfícies de fratura resultantes do ensaio com a taxa de deformação de $3 \times 10^{-7} \mathrm{~s}^{-1}$ apresentaram maior quantidade de regiões de iniciação de trincas (em cerca de $75 \%$ da borda do $\mathrm{CP}$ ) e também com a propagação delas para o centro do material (Figura 8b) a uma profundidade máxima de $600 \mu \mathrm{m}$. Isto indica que, ao diminuir a taxa de deformação, houve mais tempo para ação do meio, o que permitiu uma melhor visualização do fenômeno de CST. Quando se comparam as superfícies laterais, nas Figuras 8c e 8d, observa-se também o efeito da taxa de deformação no comportamento em CST do material. O CP da Figura 8d, ensaiado na taxa de deformação mais lenta, apresentou maior quantidade de trincas secundárias perpendiculares ao eixo de carregamento.

Com o objetivo de avaliar comparativamente a tendência à CST nas duas taxas de deformação realizou-se o calculo da taxa de propagação de trinca dividindo-se o valor da profundidade máxima da trinca pelo tempo de ruptura em cada ensaio. Verificou-se que as taxas de propagação de trincas foram da mesma ordem de grandeza para as duas condições estudas: $2 \times 10^{-7} \mathrm{~mm} . \mathrm{s}^{-1}$ para o ensaio na menor taxa de deformação $\left(1 \times 10^{-6} \mathrm{~s}^{-1}\right)$ e $4 \times 10^{-7} \mathrm{~mm} \cdot \mathrm{s}^{-1}$ para a deformação de $3 \times 10^{-7} \mathrm{~s}^{-1}$. Pode-se concluir que as duas taxas de deformação utilizadas permitiram a ocorrência do processo de CST, indicado pela existência de fratura frágil nas bordas dos CPs após os ensaios. Mas, a taxa de deformação mais lenta mostrou-se mais adequada para realizar as avaliações comparativas do processo de CST no aço inoxidável AISI 321 nas condições estudadas devido a possibilidade de visualização mais clara e detalhada do fenômeno de CST.

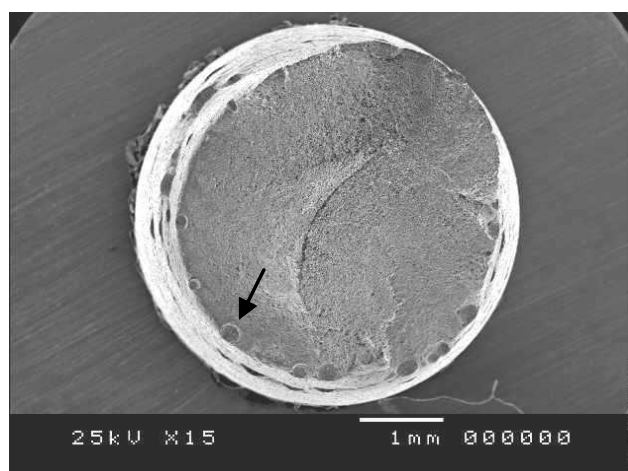

(a)

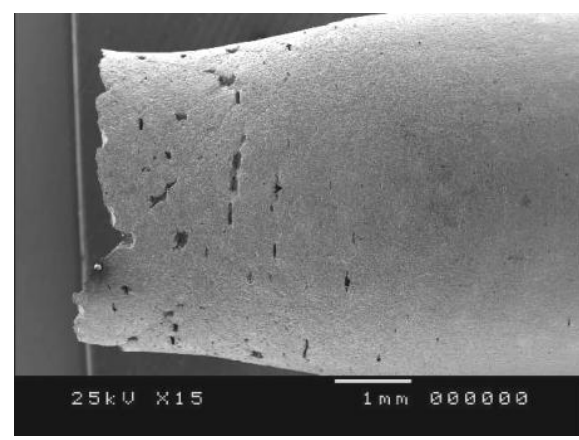

(c)

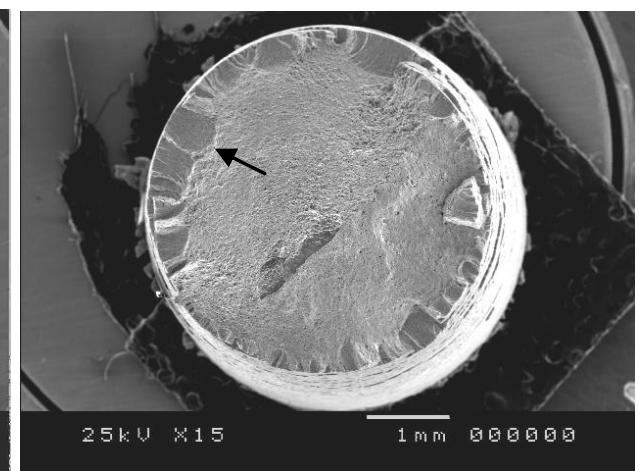

(b)

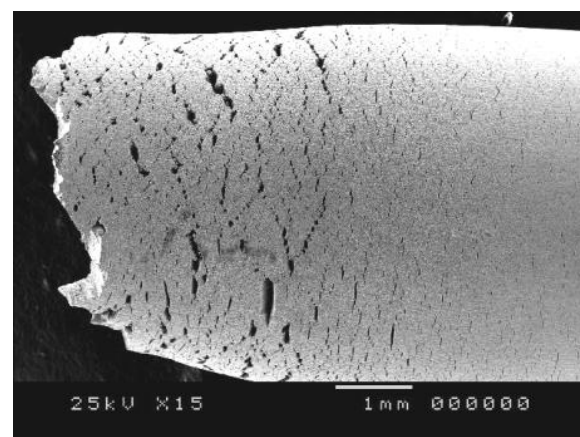

(d)

Figura 5: Microfratografias dos CPs de aço AISI 321 obtidas após os ensaios de CST com taxa de deformação de $1 \times 10^{-6} \mathrm{~s}^{-1}$ (a e c) e de $3 \times 10^{-7} \mathrm{~s}^{-1}$ (b e d). Meio: água deionizada; $288^{\circ} \mathrm{C} ; 8 \mathrm{MPa}$. 


\subsection{Avaliação do processo de corrosão sob tensão}

O comportamento em tração, ao $\mathrm{N}_{2}$ (g) e em solução, do aço inoxidável AISI 321, nos ensaios com taxa de deformação de $3 \times 10-7 \mathrm{~s}^{-1}$ foram muito similares, conforme mostrado na Figura 6 . No ensaio em nitrogênio ocorreu maior valor de deformação e menor valor de tensão de ruptura quando comparado com o ensaio em solução. A Tabela 5 mostra os resultados obtidos para deformação total, redução de área, tempo de ruptura. A susceptibilidade dos materiais ensaiados em SSRT pôde ser avaliada pelas razões de redução de áreas, de tempo de ruptura e de deformação para os corpos de prova ensaiados em solução, quando comparados aos ensaiados no meio neutro [10]. De acordo com a norma ASTM G129 - 95 [10] razões com valores próximos da unidade demonstram uma maior resistência à CST. Observa-se que as razões apresentaram valores próximos a 0,90 indicando um baixo grau de suscetibilidade do aço AISI 321 à CST e que praticamente não ocorreu perda de ductilidade deste material no meio estudado.

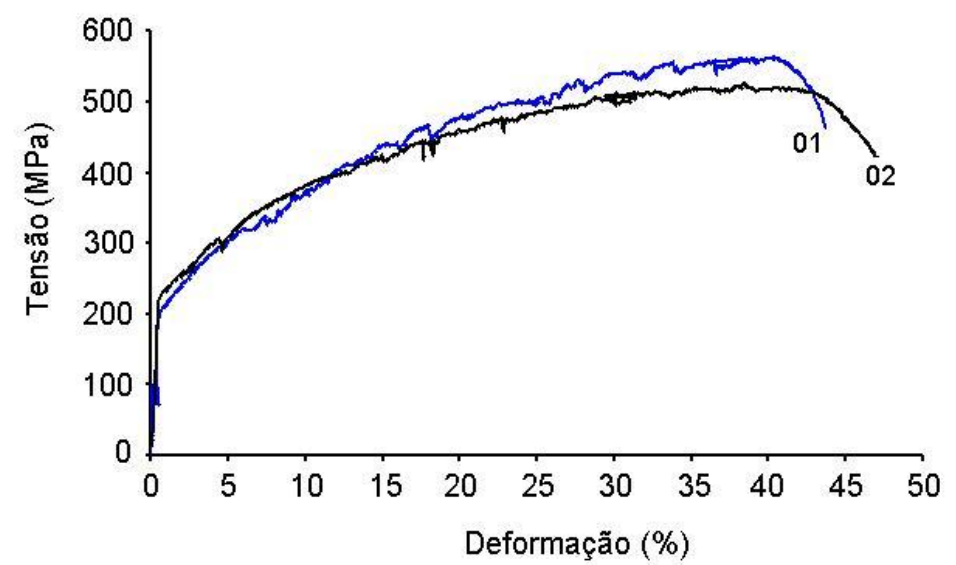

Figura 6: Curvas tensão-deformação obtidas para CPs de aço AISI 321. Ensaios de CST com taxa de deformação $3 \times 10^{-7} \mathrm{~s}^{-1}, 288^{\circ} \mathrm{C}$. Curva 01: meio aquoso, pressão $8 \mathrm{MPa}$; Curva 02: meio neutro $\left(\mathrm{N}_{2}\right)$, pressão $2 \mathrm{MPa}$.

Tabela 5: Resultados obtidos nos ensaios de taxa de deformação lenta do aço AISI 321 em ambiente aquoso e em meio neutro. Taxa de deformação de $3 \times 10^{-7} \mathrm{~s}^{-1}$.

\begin{tabular}{|c|c|c|}
\hline Ensaio & SSRT 02 & SSRT 03 \\
\hline Meio & Nitrogênio & PWR \\
\hline Velocidade de Ensaio $(\mu \mathrm{m} / \mathrm{h})$ & 34 & 33 \\
\hline Pressão $(\mathrm{MPa})$ & 2,0 & 8,0 \\
\hline Limite de Escoamento $(\mathrm{MPa})$ & 210 & 220 \\
\hline Resistência Mecânica ( MPa) & 550 & 520 \\
\hline Tempo de ruptura (h) & 451,8 & 413,3 \\
\hline Deformação $(\%)$ & 47,3 & 43,7 \\
\hline Redução de área (\%) & 55,5 & 0,92 \\
\hline Razão de Tempo de ruptura & --- & 0,92 \\
\hline Razão de Deformação & --- & 0,90 \\
\hline Razão de redução de área & --- & 50,1 \\
\hline
\end{tabular}


As curvas pressão - temperatura - tempo obtidas durante o ensaio de SSRT à taxa de deformação de $3 \times 10^{-7} \mathrm{~s}^{-1}$ são mostradas na Figura 7. É possível observar que a temperatura e a pressão mantiveram-se estáveis durante todo o ensaio.

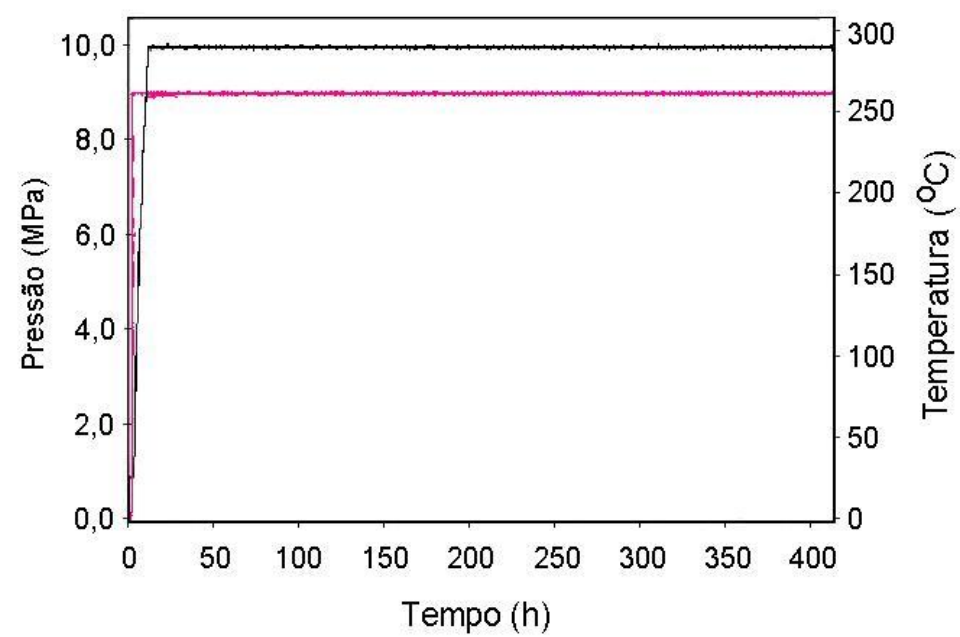

Figura 7: Curvas pressão - temperatura - tempo obtidas durante o ensaio de SSRT à taxa de deformação de $3 \times 10-7 \mathrm{~s}^{-1}$.

A Figura 8 mostra a diferenciação entre o aspecto das superfícies de fratura nas bordas e no centro do CP obtidos no meio aquoso, utilizando-se a taxa de deformação de $3 \times 10^{-7} \mathrm{~s}^{-1}$. Observou-se o aspecto frágil existente na região de iniciação de trincas por CST; o aspecto frágil - dúctil na região de transição; e a presença de dimples na região central. A presença de fratura frágil transgranular indica que o processo de CST contribuiu para a fratura do material, mas que devido a sua pequena penetração o rompimento do material foi praticamente mecânico (Figuras 9a, 9b e 9c).

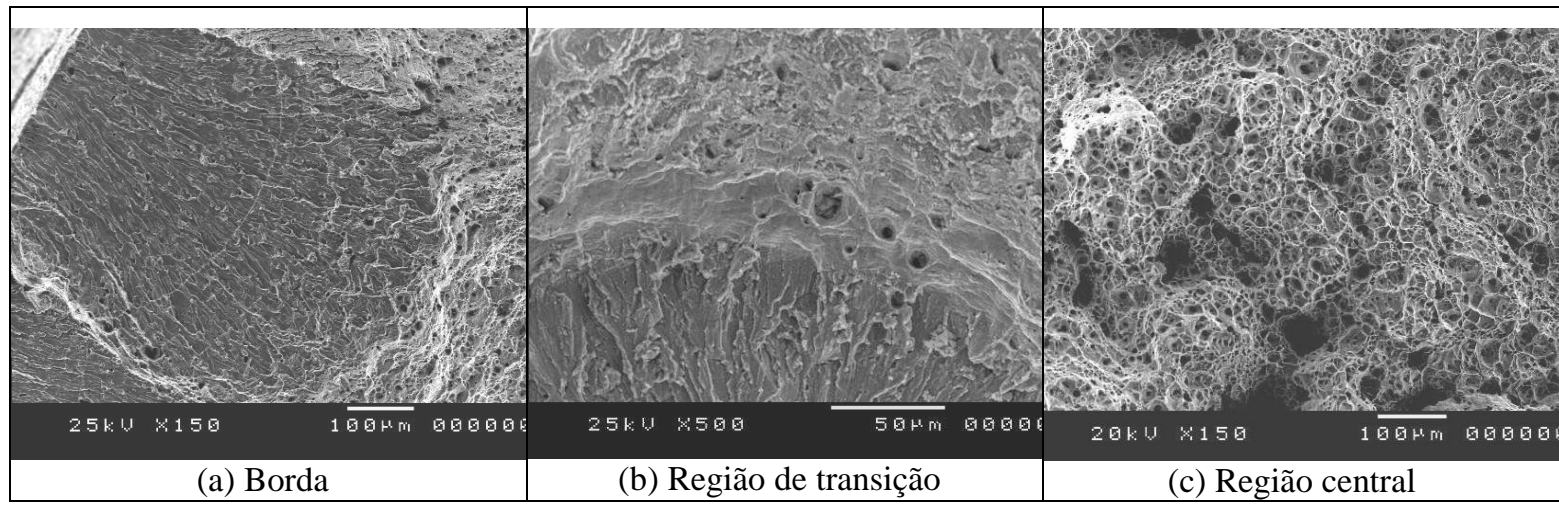

Figura 8: Superfícies de fratura dos corpos-de-prova de aço inox 321. Ensaios de CST com taxa de deformação $3 \times 10^{-7} \mathrm{~s}^{-1}$, em meio aquoso.

Nos ensaios em meio neutro $\left(\mathrm{N}_{2}\right)$, Figuras 9 a e $9 \mathrm{~b}$, observou-se a presença de dimples em toda a superfície de fratura (nas bordas e na região central) indicando a ocorrência somente de fratura dúctil decorrente de rompimento apenas mecânico. 


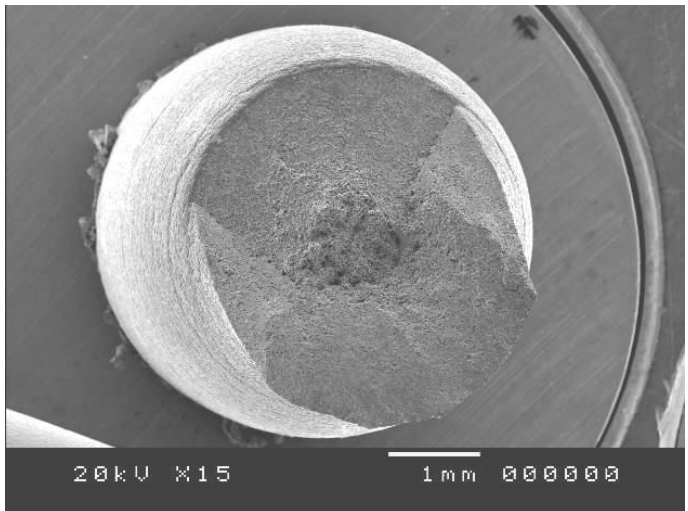

(a) Borda

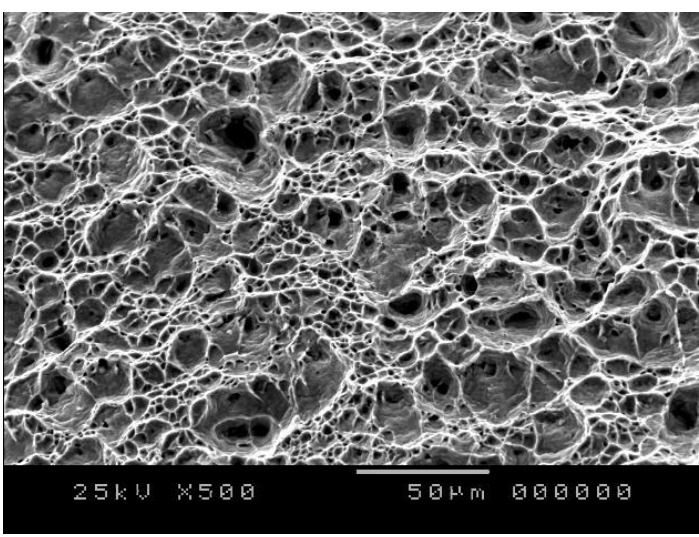

(b) Região central

Figura 9: Superfícies de fratura dos corpos-de-prova de aço inox 321. Ensaios de CST com taxa de deformação $3 \times 10^{-7} \mathrm{~s}^{-1}$, em meio neutro $\left(\mathrm{N}_{2}\right)$.

A Figura 10 mostra a superfície lateral do corpo-de-prova ensaiado em meio inerte. As fractografias mostram aspectos de fratura dúctil, conforme se evidencia pela presença de estricção na região da fratura e pela ausência de trincas secundárias.

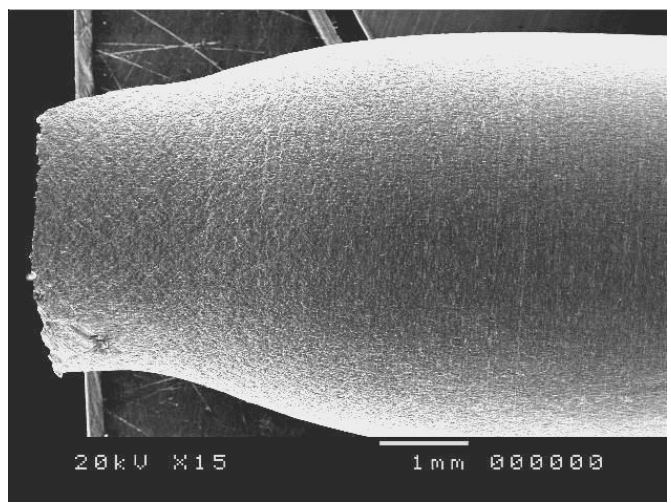

Figura 10: Microfratografia da superfície lateral do CP de aço AISI 321 ensaiado em meio neutro, com taxa de deformação de $3 \times 10^{-7} \mathrm{~s}^{-1}$, a temperatura de $288^{\circ} \mathrm{C}$ e pressão de $2 \mathrm{MPa}$.

\section{CONCLUSÃO}

1. A instalação mostrou-se adequada para a realização de ensaios de taxa de deformação lenta em ambiente similar ao encontrado em reatores nucleares (temperatura e pressão elevadas), apresentando estabilidade nos sistemas de medição de carga, deslocamento, pressão e temperatura.

2. Embora seja considerado um ensaio relativamente acelerado, através do ensaio de taxa de deformação lenta foi possível verificar o grau de suscetibilidade do aço inoxidável austenítico AISI 321 à corrosão sob tensão nas condições estudadas.

3. Foi observado que o aço AISI 321 apresenta um baixo grau de suscetibilidade à CST nas condições avaliadas. Isto pode ser comprovado pelas elevadas razões entre os tempos de falha, as deformações e as reduções de área do material nos meios aquoso e neutro.

4. Pode-se concluir que a taxa de deformação de $3 \times 10^{-7} \mathrm{~s}^{-1}$ é a mais indicada para realizar avaliações comparativas do processo de CST utilizando o ensaio de SSRT (slow strain rate test), nas condições estudadas.

\section{AGRADECIMENTOS}

Os autores agradecem a FAPEMIG e ao CNPq pelo apoio financeiro concedido para o desenvolvimento deste trabalho. 


\section{BIBLIOGRAFIA}

[1] STAEHLE, R.W., "Understanding situation-dependent ttrength: a fundamental objective in assessing the history of stress corrosion cracking", In: Proceedings of Environment-Induced Cracking of Metals, pp. 561-612, Houston, 1989.

[2] DAVIS, J. R., Corrosion - Understanding the Basics, 4 ed., ASM International, Ohio, 2008.

[3] DANKO, J.C., "Corrosion in the nuclear power industry", Metals Handbook, 9 ed. v. 13, American Society for Metals, Colorado, 1992

[4] JONES, R.H., "Corrosion: fundamentals, testing, and protection", v. 13A, ASM Handbook, ASM International, pp. 879-936, 2003.

[5] ANDRESEN, P.L., MORRA, M.M., "Stress corrosion cracking of stainless steels and nickel alloys in high-temperature water”, Corrosion Science, v. 64, n. 1, pp. 15-29, January 2008.

[6] GOMEZ-BRICENO, D., SERRANO, M., “Aleaciones base níquel em condiciones de primario de los reactores tipo PWR”, Nuclear España: Revista de la Sociedad Nuclear Española, n. 250, pp. 17-22, Marzo 2005.

[7] MAEDA, Y., NISHIMURA, R., "SCC evaluation of type 304 and 316 austenitic stainless steels in acidic chloride solutions using the slow strain rate technique", Corrosion Science, v. 46, n. 3, pp. 769-785, March 2004.

[8] JONES, H.R., Stress-Corrosion Cracking: Materials Performance and Evaluation, 2 ed., Ohio, AWSM International, 1992.

[9] NATIONAL ASSOCIATION OF CORROSION ENGINEERS - The National Association of Corrosion Engineers, Nace Standard test Method-SSRT Method for Screening Corrosion Resistant Alloys (CRAs) for Stress Corrosion Cracking in Sour Oifield Service - TMO198-2004, 2004.

[10] SCOTT, P.M., COMBRADE, P., Corrosion in Pressurized Water Reactors, v. 13C, ASM Handbook, ASM International, pp. 362-365, 2006.

[11] SCHVARTZMAN, M.M.A.M., NEVES, C.F.N., CAMPOS, W.R.C., "Facility for the study of environmentally assisted cracking”, In: Proceedings of the International Congress of Mechanical Engineering, São Paulo, November 2003.

[12] ASTM G 129-00, Standard test methods for slow strain rate testing to evaluate the susceptibility of metallic materials to environmentally assisted cracking, Annual Book of ASTM Standards, West Conshohocken, USA, 2006.

[13] CHEN, Y.Y., SHIH, H.C., LIOU, Y.M, WANG, L.H., OUNG, J.C., "Stress Corrosion Cracking of Type 321 Stainless Steels Under Simulated Petrochemical Conditions Containing Thiosulfate and Chloride", Corrosion, v. 62, n. 9, pp.781-794, September 2006.

[14] ASTM G49-85, Standard practice for preparation and use of direct tension stress-corrosion test specimen, Annual Book of ASTM Standards, Philadelphia, USA, 2006. 